\title{
Growth Hormone Receptor, Insulin-Like Growth Factor (IGF)-1, and IGF-Binding Protein-2 Expression in the Reproductive Tissues of Early Postpartum Dairy Cows
}

\author{
M. L. Rhoads, ${ }^{1}$ J. P. Meyer, S. J. Kolath, W. R. Lamberson, and M. C. Lucy ${ }^{2}$ \\ Division of Animal Sciences, University of Missouri, Columbia 65211
}

\begin{abstract}
The growth hormone/insulin-like growth factor (IGF) system plays a critical endocrine role controlling nutrient metabolism in dairy cattle. In liver, growth hormone receptor (GHR) and IGF-1 are dynamically regulated by lactation and energy balance. Less is known about the regulation of GHR, IGF-1, and IGF-binding protein mRNA in reproductive tissues (uterus, ovarian follicle, and corpus luteum). The objective was to determine expression patterns for GHR, IGF-1, and IGF-binding protein (IGFBP)-2 mRNA in the liver, uterus, dominant follicle, and corpus luteum in Holstein cows $(n=21)$ sampled at 3 times during early lactation. The first postpartum ovulation was induced with an injection of $\mathrm{GnRH}$ within $15 \mathrm{~d}$ of calving. Nine days after ovulation [23 $\pm 1 \mathrm{~d}$ postpartum; $20 \mathrm{~d}$ in milk (DIM)], the liver, uterus, dominant follicle, and corpus luteum were biopsied. Prostaglandin $\mathrm{F}_{2 \alpha}$ and $\mathrm{GnRH}$ were injected 7 and $9 \mathrm{~d}$ after each biopsy to synchronize the second ( $41 \pm 1$ d postpartum; $40 \mathrm{DIM}$ ) and third ( $60 \pm 1 \mathrm{~d}$ postpartum; 60 DIM) tissue collections. Total RNA was isolated and used for mRNA analysis by real-time quantitative reverse transcription PCR. Liver had more GHR, IGF-1, and IGFBP-2 mRNA than the reproductive tissues that were tested. Gene expression for GHR, IGF-1, and IGFPB-2 within tissues did not change across the sampling interval (20 to $60 \mathrm{DIM}$ ). The only detected change in gene expression across days was for cyclophilin in uterus (increased after 20 DIM). Parity had an effect on gene expression for GHR in corpus luteum. Neither level of milk production nor body condition score affected the amount of GHR, IGF-1, or IGFBP-2 mRNA in the respective tissues. The repeatability of gene expression within a tissue was 0.25 to 0.5 for most genes. In most instances, expression of a single gene within a
\end{abstract}

\footnotetext{
Received September 3, 2007.

Accepted January 21, 2008.

${ }^{1}$ Current address: Department of Animal Sciences, University of Arizona, Tucson 85721.

${ }^{2}$ Corresponding author: LucyM@missouri.edu
}

tissue was correlated with other genes in the same tissue but was not correlated with the same gene in a different tissue. We did not find evidence for major changes in gene expression within reproductive tissues in postpartum cows. Differences between cows (independent of their BCS and milk production) accounted for a major portion of the variation that we observed. Key words: growth hormone, insulin-like growth factor-1, insulin-like growth factor binding protein-2, reproduction

\section{INTRODUCTION}

The reproductive efficiency of dairy cattle has decreased for several decades as evidenced by decreased conception rates, more services per conception, and longer calving intervals in modern dairy cattle (Lucy, 2001). Milk production has steadily increased during the period of reproductive decline (Butler, 2000; Lucy, 2001). The greater nutritional and metabolic demands of high milk production, therefore, may be responsible for the decline in reproductive performance. Understanding the mechanisms involved in the metabolic regulation of reproduction may elucidate therapies that can be used to improve reproductive performance in high milk-producing dairy cattle.

Components of the growth hormone (GH)/IGF system play an important role in the metabolic transition that favors high milk production after calving (Lucy et al., 2001). Hepatic concentrations of growth hormone receptor (GHR) mRNA and protein decline shortly before calving and remain low during the first week of lactation (Radcliff et al., 2003a,b; Wook Kim et al., 2004). The decrease in liver GHR leads to a reduction in plasma IGF-1 concentrations. Circulating GH concentrations increase because of decreased negative feedback elicited by relatively low blood IGF-1 concentrations (Radcliff et al., 2003a,b; Wook Kim et al., 2004). Greater GH and lesser IGF-1 in blood favor a catabolic state that supports high milk production in early postpartum cows (Lucy, 2004).

Components of the GH/IGF system are predominantly found in liver but are also found in reproductive 
tissues where they serve several roles, including positive effects on steroidogenesis (Lucy, 2000; Hunter et al., 2004; Webb et al., 2004) and embryo development (Wathes et al., 1998; Watson et al., 1999; Izadyar et al., 2000; Thatcher et al., 2003). In the liver, expression of GHR and IGF-1 are affected by nutrition and metabolism (McGuire et al., 1992; Thissen et al., 1994; Roche, 2006), particularly during the periparturient period (Radcliff et al., 2006). It is unclear, however, whether the expression of GH/IGF system genes within the reproductive tract changes during the postpartum period as well. Furthermore, the possibility that metabolic signals act across all tissues in the cow to affect gene expression in a coordinated manner has not been examined. We hypothesized that the expression of components of the GH/IGF system in reproductive tissues undergoes coordinated regulation with that found in liver and responds to nutritional and metabolic signals during early lactation. The objective was to measure the mRNA expression of GHR, IGF-1, and IGF-binding protein 2 (IGFBP-2) in the liver, uterus, dominant follicle (DF) and corpus luteum $(\mathbf{C L})$ within the same cow at 3 times during the early postpartum period and to determine if stage of lactation, parity, amount of milk production or BCS influenced gene expression. The extent to which gene expression across different tissues was correlated and the repeatability of gene expression was estimated.

\section{MATERIALS AND METHODS}

\section{Animals}

The protocols for this experiment were reviewed and approved by the Institutional Animal Care and Use Committee of the University of Missouri. Multiparous lactating Holstein dairy cows with clinically normal periparturient periods were used (10 of second parity and 11 of third or greater parity; $\mathrm{n}=21$ total). Cows were housed in a free-stall barn at the University of Missouri Foremost Dairy Farm and managed according to the standard operating procedures of the dairy. Cows were milked twice daily and fed a TMR consisting of corn silage, alfalfa hay, alfalfa haylage, ground corn, soybean meal, whole cottonseeds, and a vitamin and mineral premix. General information including BW and BCS was recorded at each sample collection time. Two technicians evaluated BCS separately and the 2 scores were averaged. Milk production was measured twice daily with in-line milk meters from the time of calving until the third and final sample collection.

\section{Experimental Protocol and Biopsies}

Experimental Protocol. Postpartum ovarian follicular development was monitored every 1 to $2 \mathrm{~d}$ by
Table 1. The synchronization treatment and sample collection protocol used to collect liver, uterus, dominant follicle (DF) and corpus luteum (CL) from postpartum dairy cows at approximately 20, 40, and 60 DIM

\begin{tabular}{lll}
\hline DIM & \multicolumn{1}{c}{ Event } & \multicolumn{1}{c}{ Comment } \\
\hline 10 & GnRH injection & Ovulate DF \\
11 & Ultrasound & Verify DF ovulation \\
20 & Tissue collection & \\
27 & PGF $_{2 \alpha}$ injection & Regress CL \\
29 & GnRH injection $_{30}$ & Ovulate DF \\
39 & Ultrasound & Verify DF ovulation \\
46 & Tissue collection & \\
48 & PGF $_{2 \alpha}$ injection & Regress CL \\
49 & GnRH injection & Ovulate DF \\
58 & Ultrasound & Verify DF ovulation \\
\hline
\end{tabular}

transrectal ultrasonography (Aloka $500 \mathrm{~V}$ ultrasound scanner with a 7.5-MHz probe, Aloka Co. Ltd., Tokyo, Japan) beginning approximately $7 \mathrm{~d}$ after calving. An injection of GnRH (100 $\mu \mathrm{g}$ of Cystorelin, Merial Ltd., Iselin, NJ) was administered i.m. to induce ovulation when there was a growing DF (11 mm or greater in diameter). The DF was classified as having ovulated if it was undetectable by ultrasound on the day after the GnRH injection. Nine days after ovulation a first-wave $\mathrm{DF}$ and functional CL (arising from the GnRH-induced ovulation) were present on the ovary. Samples of the liver, uterus, DF, and CL were collected (described subsequently).

Seven days after the first sample collection, an injection of $\mathrm{PGF}_{2 \alpha}$ (25 mg of Lutalyse, Pfizer Inc., New York, NY) was administered i.m. to regress the CL. Two days later, an injection of $\mathrm{GnRH}$ was given to cause ovulation of the DF. Ovulation was verified by ultrasound. Nine days after ovulation, a second set of samples was collected (liver, uterus, DF, and CL). The injection sequence was repeated to prepare the cows for a third sample collection that was scheduled to occur at approximately $58 \mathrm{~d}$ postpartum. The treatment and sample collection protocol is presented in Table 1.

Uterine Biopsies. Uterine biopsies were collected transcervically with a semiflexible biopsy instrument ( $3 \mathrm{~mm} \times 450 \mathrm{~mm}$, semiflexible forceps with a Palmer Jacobs jaw, Richard Wolf Medical Instruments Corporation, Vernon Hills, IL). The procedure was described in a previous publication (Rhoads et al., 2008). Uterine tissue was collected from both horns at a location approximately $8 \mathrm{~cm}$ beyond the internal uterine bifurcation. Tissue samples were frozen in liquid nitrogen and stored at $-80^{\circ} \mathrm{C}$ until RNA extraction. Tissue collection was not successful from 2 cows so the total number of uterine tissue samples in these analyses was 61 .

Follicular Aspirations. The DF was collected by ultrasound-guided transvaginal follicular aspiration. 
The area above the first intercoccygeal space was clipped and disinfected with an iodine scrub solution and $70 \%$ ethanol. Lidocaine $(5 \mathrm{~mL}, 2 \%$ lidocaine hydrochloride solution) was injected into the first intercoccygeal space and time was allowed for the anesthesia to take effect. The vulva and perianal area were cleaned and disinfected with iodine scrub solution.

An Aloka 500V ultrasound scanner equipped with a $7.5-\mathrm{MHz}$ probe was used for the follicle aspiration procedure. The ultrasound probe was enclosed within a custom-made handle. The handle enclosed the probe cord and fixed the head of the probe at a $30^{\circ}$ angle relative to the needle guide. The needle guide ended at the base of the probe, just above the probe head.

The probe and handle were lubricated with a sterile water-based lubricant and positioned in the vagina slightly posterior to the cervix. The ovary containing the DF was manipulated toward the ultrasound probe so that the DF could be inspected and measured before aspiration. A 17-gauge double lumen aspiration needle (Cook Australia, Queensland, Australia) was passed through the needle guide of the handle and then through the vagina. Approximately $2 \mathrm{~mL}$ of sterile saline was flushed through the primary lumen of the needle to remove debris that could interfere with the aspiration. The aspiration needle was guided through the stroma of the ovary and into the DF. The follicular fluid and cells were retrieved and up to $10 \mathrm{~mL}$ of sterile saline was immediately flushed through the follicular cavity to increase the number of recovered granulosa cells.

The follicular cells were immediately pelleted by centrifugation, and the follicular fluid/saline solution was decanted. The cells were frozen in liquid nitrogen and stored at $-80^{\circ} \mathrm{C}$. The follicular fluid and saline mixture was frozen at $-20^{\circ} \mathrm{C}$ for subsequent analysis of hormones. Tissue from DF was not successfully obtained at each sample collection and multiple DF were present at some sample collections ( $\mathrm{n}=5$ collections with multiple DF). When 2 estrogenic DF were found, both were collected but their data were excluded in the subsequent data analyses. Follicles that had estradiol to progesterone ratios less than or equal to $1.0(n=3)$ were classified as atretic and were also excluded. The numbers of follicles used in the gene expression analyses were 10, 16, and 11 for the first, second, and third sample collections, respectively.

Luteal Biopsies. A sample of the CL was collected by needle biopsy immediately following the follicular aspiration, while the cow remained anesthetized. The biopsy needle (18-gauge, $48 \mathrm{~cm}$ in length with a $20-\mathrm{mm}$ notch, US Biopsy, Franklin, IN) was passed through the needle guide of the ultrasound probe handle and a sample of the CL was collected by transvaginal biopsy.
The luteal tissue was placed in a screw-cap microcentrifuge tube and frozen in liquid nitrogen. The samples were stored at $-80^{\circ} \mathrm{C}$ until RNA isolation. Tissue from CL was not successfully obtained at each sample collection. The numbers of CL used in the gene expression analyses were 14, 19, and 18 for the first, second, and third sample collections, respectively.

Liver Biopsies. Liver samples were collected by needle biopsy as described by Rhoads et al. (2008). The tissue was frozen in liquid nitrogen and stored at $-80^{\circ} \mathrm{C}$ until RNA extraction. Tissue collection was not successful from one cow so the total number of liver tissue samples in these analyses was 62 .

Blood Samples. Blood samples were collected by coccygeal venipuncture on each of the 3 sample collection dates. Samples were collected into an evacuated glass tube containing EDTA (BD Vacutainer; Franklin Lakes, NJ) and placed on ice for transport to the laboratory. Plasma was harvested from the blood samples following centrifugation at $1,500 \times g$ for $15 \mathrm{~min}$, and subsequently frozen at $-20^{\circ} \mathrm{C}$.

\section{RNA Isolation}

Total cellular RNA was isolated from liver and uterine tissues using the TRIzol reagent (Invitrogen, Carlsbad, CA) according to the manufacturer's instructions. The RNA from the DF and CL was isolated using a column method (RNAqueous, Ambion, Austin, TX) because of the small size of samples.

The RNA content of each sample was calculated based on absorbance at $260 \mathrm{~nm}$. The quality of the RNA was evaluated by calculating the ratio of absorbance at 260 and $280 \mathrm{~nm}$, followed by gel electrophoresis $(0.8 \%$ agarose gel in $0.09 M$ Tris-borate and $0.002 M$ EDTA buffer with $0.5 \mu \mathrm{g} / \mathrm{mL}$ of ethidium bromide). The RNA was stored at $-80^{\circ} \mathrm{C}$ until reverse transcription (RT) into cDNA with the SuperScript First Strand Synthesis System for RT-PCR (Invitrogen). The cDNA was stored at $-20^{\circ} \mathrm{C}$.

\section{Real-Time Quantitative RT-PCR}

The amount of GHR, IGF-1, IGFBP-2, and cyclophilin mRNA in liver, uterus, DF, and CL were measured by real-time quantitative RT-PCR (Taqman, Applied Biosystems; Foster City, CA). The primer pairs, probes, and amplification efficiencies for each individual assay were reported previously (Rhoads et al., 2008). The GHR mRNA assayed herein is identical to the total GHR (tGHR) assay in Rhoads et al. (2008). The $25-\mu \mathrm{L}$ reactions were prepared with $100 \mathrm{n} M$ of probe and 500 $\mathrm{n} M$ of primer using the Brilliant QPCR Plus Core Reagent Kit (Stratagene, La Jolla, CA). A no-template 
control and 3 internal control samples (high, medium, and low) were run in triplicate on every 96 -well reaction plate. Twenty-five nanograms of sample was run in triplicate in each assay. The PCR reactions were performed and fluorescence was quantified with the ABI PRISM 7700 Sequence Detector (Applied Biosystems). Analyses of amplification plots were performed with the Sequence Detection Software (Applied Biosystems). An internal control sample (cDNA sample from fetal liver that was used in every assay) was included in each RT-PCR plate. This internal control was used as a reference sample for calculating relative changes in mRNA expression within each individual sample. The fold difference between the internal control sample and the individual sample was calculated by using the amplification efficiencies reported in Rhoads et al. (2008). For each respective target gene, the fold difference for the individual sample was equal to the amplification efficiency raised to the power of the internal control cycle threshold $\left(\mathrm{C}_{\mathrm{T}}\right)$ minus the sample $\mathrm{C}_{\mathrm{T}}$.

\section{Hormone Assays}

Plasma GH (Gorewit, 1981) and IGF-1 (Rhoads et al., 2008) concentrations were measured by validated homologous double antibody RIA. The plasma GH and IGF-1 concentrations were each measured in single assays. The intraassay $\mathrm{CV}$ was $6.6 \%$ for the $\mathrm{GH}$ assay and $8.5 \%$ for the IGF-1 assay. Plasma estradiol and plasma progesterone were analyzed by validated RIA (Kirby et al., 1997). Plasma estradiol and progesterone concentrations were measured in single assays with intraassay CV of 13.4 and 9.4\%, respectively. Follicular fluid progesterone concentrations were also measured in a single RIA with an intraassay CV of $9.2 \%$. Follicular fluid estradiol concentrations were measured with an estradiol kit (Ultra-sensitive Estradiol, Diagnostic Systems Laboratories Inc., Webster, TX) in a single assay with a CV of $9.8 \%$.

\section{Statistical Analysis}

Data were analyzed by using the MIXED procedure of SAS (SAS Institute Inc., Cary, NC). The compound symmetry, unstructured and autoregressive 1 covariance structures were tested and the most appropriate (lowest Akaike's information criterion, Akaike's information criterion with correction, and Bayesian information criterion values) was used for each analysis. Sample collection day was included in the model as the repeated variable and cow nested within parity was included as a random effect. The model used for the analyses of milk production, BCS and BW included the effects of day (in this case, sample collection day), parity
( 2 or $\geq 3$ ), and day by parity. The model used for the analyses of plasma hormones (IGF-1, GH, progesterone, and estradiol) and ovarian structures (diameters of the DF and CL) included the effects of day, parity (2 or $\geq 3$ ), day by parity, milk production (kilograms of milk produced on the sample day as a continuous variable), and BCS (BCS on the sample day; continuous variable). The fold difference for gene expression (GHR, IGF-1, IGFBP-2, and cyclophilin expression relative to internal control sample) was analyzed in 2 ways. The first set of analyses (tissue model) included the effect of day, tissue, day by tissue, parity, day by parity, milk production, and BCS. The second set of analyses was performed for data that were sorted by tissue and included the effects of day, parity, day by parity, milk production, and BCS. Results are reported as least squares means \pm SEM. Separation of means was conducted with the Tukey procedure of SAS. Repeatability of the dependent variables was calculated as the between cow variance divided by the sum of the between cow variance and the residual variance. The REG procedure of SAS was used for linear regression. Statistical significance was declared at $P<0.05$.

\section{RESULTS}

\section{Hormonal and Physiological Changes During Early Lactation}

Milk Production, BCS, and BW. The first, second, and third sample collections occurred at $23 \pm 1,41 \pm 1$, and $60 \pm 1 \mathrm{~d}$ postpartum, respectively. For simplicity these collection days will hereafter be referred to as 20,40 , and 60 DIM, respectively. There were effects of parity $(P<0.01)$ and day $(P<0.001)$ on milk production. Second-parity cows produced less milk than third or greater parity cows (44 \pm 1 and $50 \pm 1 \mathrm{~kg} / \mathrm{d}$ for second parity and third or greater parity, respectively) and milk production at 20 DIM was less than at 40 or 60 DIM ( $45 \pm 1,49 \pm 1$, and $47 \pm 1 \mathrm{~kg} / \mathrm{d}$ for 20,40 , and 60 DIM, respectively). There was a parity by day interaction $(P<0.01)$ for BCS because second-parity cows gained BCS but third or greater parity cows lost BCS postpartum $(2.38 \pm 0.07,2.43 \pm 0.07$, and $2.42 \pm 0.07$ for younger cows and $2.38 \pm 0.07,2.26 \pm 0.07$, and 2.23 \pm 0.07 for older cows at 20,40 , and 60 DIM, respectively). The BW $(596 \pm 8 \mathrm{~kg})$ was not affected by parity, day, or day by parity.

Plasma IGF-1 and GH. There was an effect of parity on plasma concentrations of IGF-1 because second-parity cows had greater concentrations of plasma IGF-1 than third or greater parity cows $(79.4 \pm 4.3$ vs. $62.7 \pm$ $4.2 \mathrm{ng} / \mathrm{mL} ; P<0.05)$. There was no effect of parity on plasma GH concentrations $(2.9 \pm 0.1 \mathrm{ng} / \mathrm{mL})$. There was 


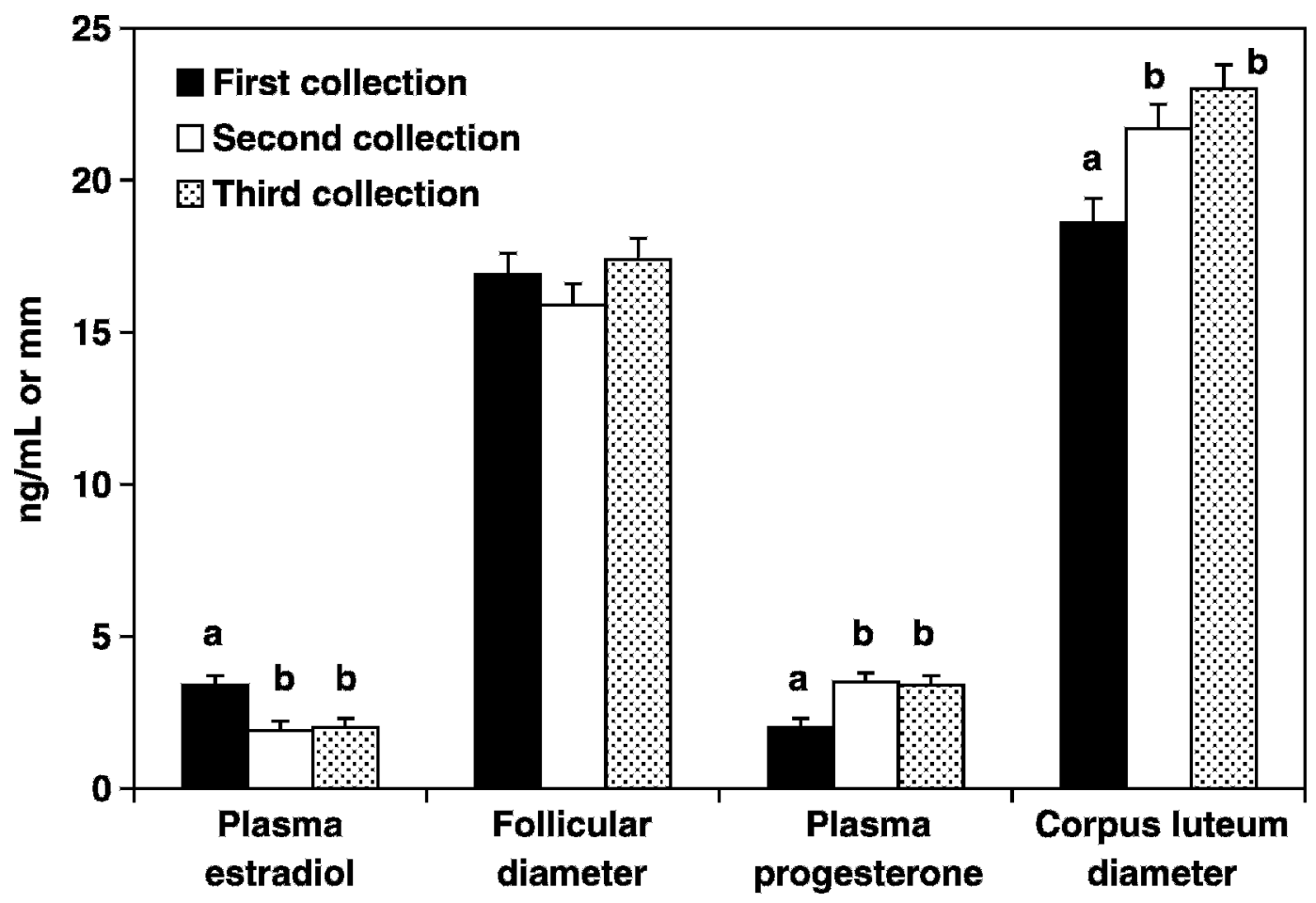

Figure 1. Plasma estradiol, dominant follicle diameter, plasma progesterone, and corpus luteum diameter at the first, second, and third sample collection time points $(20,40$, and $60 \mathrm{DIM}){ }^{\mathrm{a}, \mathrm{b}}$ Bars with different letters differ at $P<0.05$. The diameter of the dominant follicle did not differ significantly among the 3 collection times.

no effect of sample collection day on either plasma IGF1 or plasma GH.

Ovarian Structures and Hormones. The diameter of the ovulated DF at the time of GnRH injection was smaller before the first sample collection than before the second sample collection $(13.9 \pm 0.4 \mathrm{~mm}$ and 16.1 $\pm 0.6 \mathrm{~mm}$, respectively; $P<0.05)$. The diameter of the DF before the third sample collection $(15.6 \pm 0.8 \mathrm{~mm})$ was intermediate in size and did not differ from the other sample times. The diameters of the DF that were aspirated for hormone and gene expression analyses did not differ at 20,40, and 60 DIM (Figure 1), but there was an effect of parity $(P<0.02)$ and a linear effect of milk production $(P<0.01)$ on DF diameter. Second-parity cows had larger DF than third or greater parity cows $(18.1 \pm 0.7$ vs. $15.4 \pm 0.7 \mathrm{~mm})$ and the diameter of the DF increased with greater milk production $(0.3 \pm 0.1 \mathrm{~mm}$ per $\mathrm{kg}$ of milk produced). Follicular fluid estradiol to progesterone ratios were not affected by parity, day, milk production, or BCS. Relative to 20 DIM, the diameter of the CL and plasma progesterone concentrations were greater $(P<0.001$ and $P<0.001$, respectively) but plasma estradiol concentrations were less $(P<0.01)$ at 40 and 60 DIM (Figure 1$)$. There were no effects of parity, milk production, or BCS on the diameter of the CL or plasma concentrations of estradiol or progesterone.

\section{Gene Expression in Reproductive Tissues During Early Lactation}

Relative Amounts of GHR, IGF-1, IGFBP-2, and Cyclophilin in Tissues. There was an effect of tissue on the expression of GHR, IGF-1, IBFBP-2, and cyclophilin (Table 2). Liver had a greater amount of GHR, IGF1 , and IGFBP-2 than reproductive tissues (uterus, DF, and CL). The CL had more GHR and IGF-1 than either uterus or DF. The amount of IGFBP-2 was similar for reproductive tissues. The amount of cyclophilin was greatest in CL and least in uterus.

Effects of Sample Day, Parity, Milk Production, and BCS. There were no effects of sample day, parity, milk production, or BCS on the expression of GHR, IGF1, IGFBP-2, or cyclophilin in liver or DF. Within the CL, there was an effect of parity on GHR expression because the amount of GHR mRNA was greater in third or greater parity cows compared with second-parity cows $(11.6 \pm 1.3$ vs. $5.1 \pm 1.4 ; P<0.01)$; other effects in the model were not significant for CL GHR. There were no effects of day, parity, milk production, or BCS on 
Table 2. The relative amount of mRNA (LSM \pm SEM) for growth hormone receptor (GHR), IGF-1, IGFbinding protein 2 (IGFBP2), and cyclophilin in liver, uterus, dominant follicle (DF), and corpus luteum (CL) sampled at 20,40 , and 60 DIM $^{1}$

\begin{tabular}{lcrcc}
\hline & \multicolumn{4}{c}{ Tissue } \\
\cline { 2 - 5 } Gene & \multicolumn{1}{c}{ Liver } & Uterus & DF & CL \\
\hline GHR $^{2}$ & $26.76 \pm 0.95^{\mathrm{a}}$ & $0.08 \pm 0.95^{\mathrm{c}}$ & $1.09 \pm 1.22^{\mathrm{c}}$ & $8.69 \pm 1.04^{\mathrm{b}}$ \\
IGF-1 $^{2}$ & $18.38 \pm 0.85^{\mathrm{a}}$ & $2.83 \pm 0.86^{\mathrm{c}}$ & $3.82 \pm 1.12^{\mathrm{c}}$ & $6.56 \pm 0.93^{\mathrm{b}}$ \\
IGFBP2 $^{2}$ & $39.26 \pm 1.24^{\mathrm{a}}$ & $-0.02 \pm 1.25^{\mathrm{b}}$ & $0.72 \pm 1.64^{\mathrm{b}}$ & $0.11 \pm 1.37^{\mathrm{b}}$ \\
Cyclophilin $^{2}$ & $1.31 \pm 0.08^{\mathrm{c}}$ & $0.65 \pm 0.08^{\mathrm{d}}$ & $1.67 \pm 0.10^{\mathrm{b}}$ & $2.20 \pm 0.09^{\mathrm{a}}$ \\
\hline
\end{tabular}

${ }^{\mathrm{a}-\mathrm{d}}$ Least squares means within a row with different superscripts differ $(P<0.05)$.

${ }^{1}$ The data are fold differences relative to internal control within each assay plate.

${ }^{2}$ Effect of tissue, $P<0.001$.

IGF-1, IGFBP-2, and cyclophilin in the CL, or GHR and IGF-1 in the uterus. There was an effect of parity $(P<$ $0.05 ; 0.06 \pm 0.02$ vs. $-0.01 \pm 0.02$ for second and third or greater parity cows, respectively) and milk production $(P<0.05 ; 0.006 \pm 0.003$ unit increase in uterine IGFBP2 per $\mathrm{kg}$ of milk produced) for IGFBP-2 in the uterus. There was an effect of day $(P<0.05)$ for uterine cyclophilin expression because the amount of cyclophilin in uterus was greatest on 20 DIM $(0.79 \pm 0.08)$ compared with 40 DIM $(0.59 \pm 0.08)$ or 60 DIM $(0.58$ $\pm 0.08)$.

Repeatability of Gene Expression. The repeatability (r) for gene expression was typically positive. Most repeatabilities fell within the range of 0.25 to 0.50 (Table 3). For all tissues except CL, the greatest repeatability among the tested genes was found for IGF-1. The greatest observed repeatability was for IGF-1 in follicle $(r=0.91)$. For comparison, the repeatabilities for physical characteristics measured for cows in the trial were 0.78 for milk production and 0.85 for BCS. The repeatabilities for plasma IGF-1, GH, progesterone, and estradiol were $0.58,0.51,0.20$, and 0.04 , respectively.

Correlation in Gene Expression Across and Within Tissues. For the same cow and day, estimates of gene expression for a single gene in one tissue were generally not correlated with gene expression for the same or a different gene in a second tissue. The only exceptions were a positive correlation between cyclophi-

Table 3. Repeatability for gene expression for growth hormone receptor (GHR), IGF-1, IGF-binding protein-2 (IGFBP2), and cyclophilin in liver, uterus, dominant follicle (DF), and corpus luteum (CL) sampled at 20, 40, and 60 DIM

\begin{tabular}{lcccc}
\hline & \multicolumn{4}{c}{ Tissue } \\
\cline { 2 - 5 } Gene & Liver & Uterus & DF & CL \\
\hline GHR & 0.27 & 0.27 & 0.07 & 0.41 \\
IGF-1 & 0.47 & 0.65 & 0.91 & 0.14 \\
IGFBP2 & 0.18 & -0.09 & 0.53 & 0.41 \\
Cyclophilin & 0.25 & 0.49 & -0.32 & 0.46 \\
\hline
\end{tabular}

lin in the CL and cyclophilin in the DF $(\mathrm{r}=0.49 ; P<$ 0.01 ) and between IGF-1 in the CL and cyclophilin in the $\mathrm{DF}(\mathrm{r}=0.51 ; P<0.01)$. Within a tissue, however, the expression of one gene was typically correlated with the expression of a second gene in the same tissue (Table 4). This was most notable for GHR that was highly correlated with cyclophilin in liver, uterus, DF, and CL. The GHR expression was also correlated with IGF-1 expression in all tissues except DF. Likewise, IGF-1 and IGFBP-2 were correlated with cyclophilin in all tissues except DF. The expression of IGF-1 was correlated with IGFBP-2 expression in all tissues except uterus. The expression of IGF-1 in liver was correlated with blood IGF-1 ( $\mathrm{r}=0.34 ; P<0.01)$ but IGF-1 expression in other tissues (uterus, DF, and CL) was not correlated with blood IGF-1.

Although the correlations were similar in terms of magnitude, regression lines for the relationship between 2 genes were different for individual tissues (Table 4 and Figure 2; $P<0.001$ ). For the regression of GHR expression on cyclophilin expression, the slope of the regression line differed by nearly 85 -fold for liver compared with uterus (Figure 2A). Likewise for the regression of IGF-1 on cyclophilin, the greatest slope was observed for liver. Uterus had the lesser slope (Figure 2B). The regression of IGF-1 on GHR yielded a nearly identical slope for liver and CL but the regression for uterine tissue was distinctly different with a numerically greater $r$ and a steeper slope (Table 4; Figure 3).

\section{DISCUSSION}

In this study, liver, uterus, DF, and CL were collected from the same cow at approximately 20 -d intervals from 20 to 60 DIM. The study was unique because multiple tissues were sampled from the same cow and assayed for the same genes within the GH/IGF system. We hypothesized that the expression of components of the $\mathrm{GH} / \mathrm{IGF}$ system in reproductive tissues undergoes coor- 
Table 4. Linear regressions for the relationship between the expression of 2 genes within the same tissue for growth hormone receptor (GHR), IGF-1, IGF-binding protein-2 (IGFBP-2), and cyclophilin in liver, uterus, dominant follicle (DF), and corpus luteum (CL) sampled at 20, 40, and $60 \mathrm{DIM}^{1}$

\begin{tabular}{lllrlr}
\hline & \multicolumn{5}{c}{ Regression ${ }^{1}$} \\
Tissue & \multicolumn{1}{c}{$\hat{\mathrm{y}}$} & \multicolumn{1}{c}{$\mathrm{x}$} & \multicolumn{1}{c}{$\mathrm{b}_{0}$} & \multicolumn{1}{c}{$\mathrm{b}_{1}$} & $\mathrm{r}$ \\
\cline { 2 - 6 } Liver & GHR & Cyclophilin & $-9.70 \pm 6.56$ & $27.84 \pm 4.9^{* * *}$ & 0.59 \\
Uterus & GHR & Cyclophilin & $-0.11 \pm 0.03^{* * *}$ & $0.33 \pm 0.04^{* * *}$ & 0.74 \\
DF & GHR & Cyclophilin & $-0.34 \pm 0.30$ & $1.10 \pm 0.17^{* * *}$ & 0.74 \\
CL & GHR & Cyclophilin & $-1.62 \pm 1.19$ & $4.65 \pm 0.49^{* * *}$ & 0.80 \\
Liver & IGF-1 & Cyclophilin & $-14.12 \pm 5.80^{*}$ & $24.79 \pm 4.36^{* * *}$ & 0.59 \\
Uterus & IGF-1 & Cyclophilin & $-1.05 \pm 0.39^{* *}$ & $6.05 \pm 0.54^{* * *}$ & 0.83 \\
CL & IGF-1 & Cyclophilin & $3.34 \pm 1.06^{* *}$ & $1.45 \pm 0.44^{* *}$ & 0.43 \\
Liver & IGFBP-2 & Cyclophilin & $-7.02 \pm 10.47$ & $35.33 \pm 7.85^{* * *}$ & 0.50 \\
Uterus & IGFBP-2 & Cyclophilin & $-0.04 \pm 0.03$ & $0.10 \pm 0.04^{*}$ & 0.29 \\
CL & IGFBP-2 & Cyclophilin & $-0.03 \pm 0.06$ & $0.14 \pm 0.03^{* * *}$ & 0.62 \\
Liver & IGF-1 & GHR & $8.34 \pm 3.02^{* *}$ & $0.37 \pm 0.10^{* * *}$ & 0.42 \\
Uterus & IGF-1 & GHR & $1.53 \pm 0.24^{* * *}$ & $12.52 \pm 1.39^{* * *}$ & 0.76 \\
CL & IGF-1 & GHR & $4.50 \pm 0.78^{* * *}$ & $0.24 \pm 0.08^{* *}$ & 0.41 \\
Liver & IGFBP-2 & GHR & $9.89 \pm 3.78^{* *}$ & $1.10 \pm 0.13^{* * *}$ & 0.74 \\
Uterus & IGFBP-2 & GHR & $-0.01 \pm 0.02$ & $0.35 \pm 0.09^{* * *}$ & 0.46 \\
DF & IGFBP-2 & GHR & $0.30 \pm 0.34$ & $0.54 \pm 0.21^{*}$ & 0.41 \\
CL & IGFBP-2 & GHR & $0.09 \pm 0.05 \dagger$ & $0.02 \pm 0.01^{* * *}$ & 0.57 \\
Liver & IGFBP-2 & IGF-1 & $27.7 \pm 4.21^{* * *}$ & $0.63 \pm 0.20^{* *}$ & 0.37 \\
DF & IGFBP-2 & IGF-1 & $0.44 \pm 0.26 \dagger$ & $0.17 \pm 0.05^{* *}$ & 0.50 \\
CL & IGFBP-2 & IGF-1 & $0.12 \pm 0.07 \dagger$ & $0.02 \pm 0.01^{* *}$ & 0.36 \\
\hline
\end{tabular}

${ }^{1}$ Only statistically significant regressions $(P<0.05)$ are shown.

${ }^{2}$ The linear regression equation $\left(\hat{y}=b_{0}+b_{1} \times x\right)$ was calculated by using PROC REG of SAS (SAS Institute Inc., Cary, NC). Data for $b_{0}$ and $b_{1}$ are the parameter estimate \pm SEM.

$* * * P<0.001, * * P<0.01, * P<0.05 ; \dagger P<0.10$ denotes difference from zero ( $t$-test).

dinated regulation with that found in liver and responds to nutritional and metabolic signals during early lactation. We failed to confirm this hypothesis with this work. The primary findings from this work were that the amount of gene expression differed for the respective tissues but changed little within a tissue during the studied period (20 to 60 DIM). We also found that gene expression was moderately repeatable and the repeatability was approximately equivalent in magnitude to metabolic hormones assayed in this trial (GH and IGF-1). This finding implies that the expression of genes within a variety of tissues is controlled by the unique characteristics of the individual cow.

The trial design included a reproductive management program that enabled appropriately timed tissue collections (Table 1). A series of GnRH and $\mathrm{PGF}_{2 \alpha}$ injections were used to enable the collection of a DF and a CL that were on $\mathrm{d} 10$ of the induced estrous cycle $(\mathrm{GnRH}$ injection $=\mathrm{d} 0$ ). All cows responded to the GnRH and $\mathrm{PGF}_{2 \alpha}$ injections in the appropriate manner at all stages of lactation. We found that by using this approach we could collect a DF that was estrogenic and mature in size (Figure 1). We were able to collect all cows during the luteal phase and this consistent sampling time was important because gene expression within reproductive tissues increases at estrus (Rhoads et al., 2008). The process did reveal some nuances of ovarian development in postpartum cows. For example, the DF were similar in size at the time of all 3 aspirations but the plasma concentrations of estradiol were greatest at the time of the first collection (20 DIM; Figure 1). We also observed lower blood progesterone and smaller CL at 20 DIM. The first postpartum DF was used for the first ovulation (20 DIM sample). This $\mathrm{DF}$ was smaller at GnRH injection than the DF used for later sample collections. Ovulation of a small DF leads to the development of a small CL (Vasconcelos et al., 1999; Quintans et al., 2004). The smaller CL size and lower blood progesterone concentrations, therefore, were most likely a consequence of the smaller DF that ovulated to create the CL for the first sample collection. Perhaps the lower blood progesterone fed back on the pituitary and hypothalamus to affect LH pulsatility (theoretically greater when progesterone is lower). The change in LH pulsatility may have affected the estrogenic capacity of the follicle and caused elevated plasma estradiol (Figure 1).

Our original intent was to capture cows that were recoupling their somatotropic axis. The cows on this trial did have greater milk production at the later sample times but BCS and BW indicated that the cows maintained a stable energetic balance throughout the 


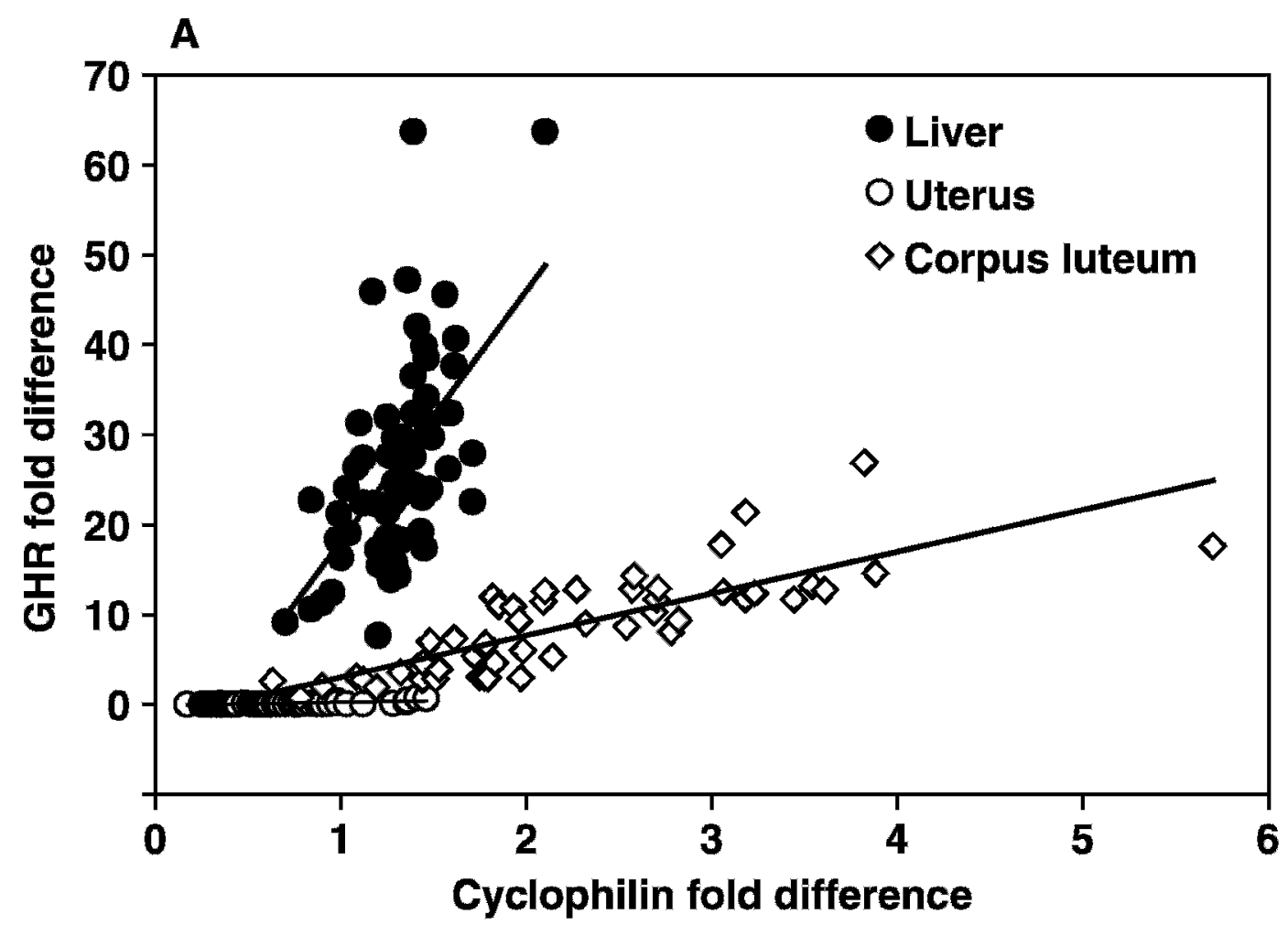

B

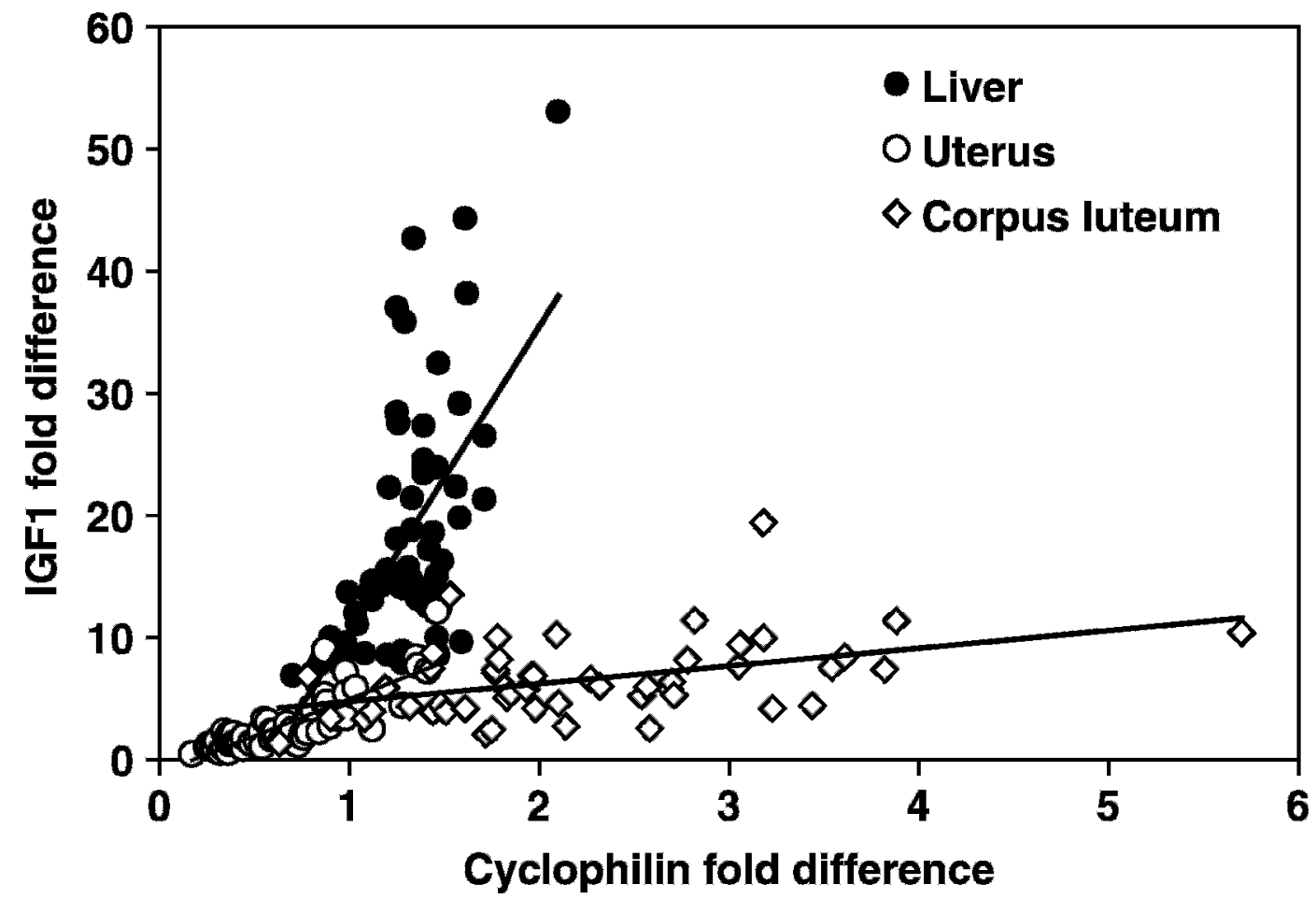

Figure 2. Regression of A) growth hormone receptor (GHR) gene expression on cyclophilin gene expression and B) IGF-1 gene expression on cyclophilin gene expression for liver, uterus, and corpus luteum. The equations for the regression lines are presented in Table 4. In each case the regression is highly significant (different from 0) but the slope of the regression line depends on the tissue. Data are for cows sampled at 20,40 , and 60 DIM. 


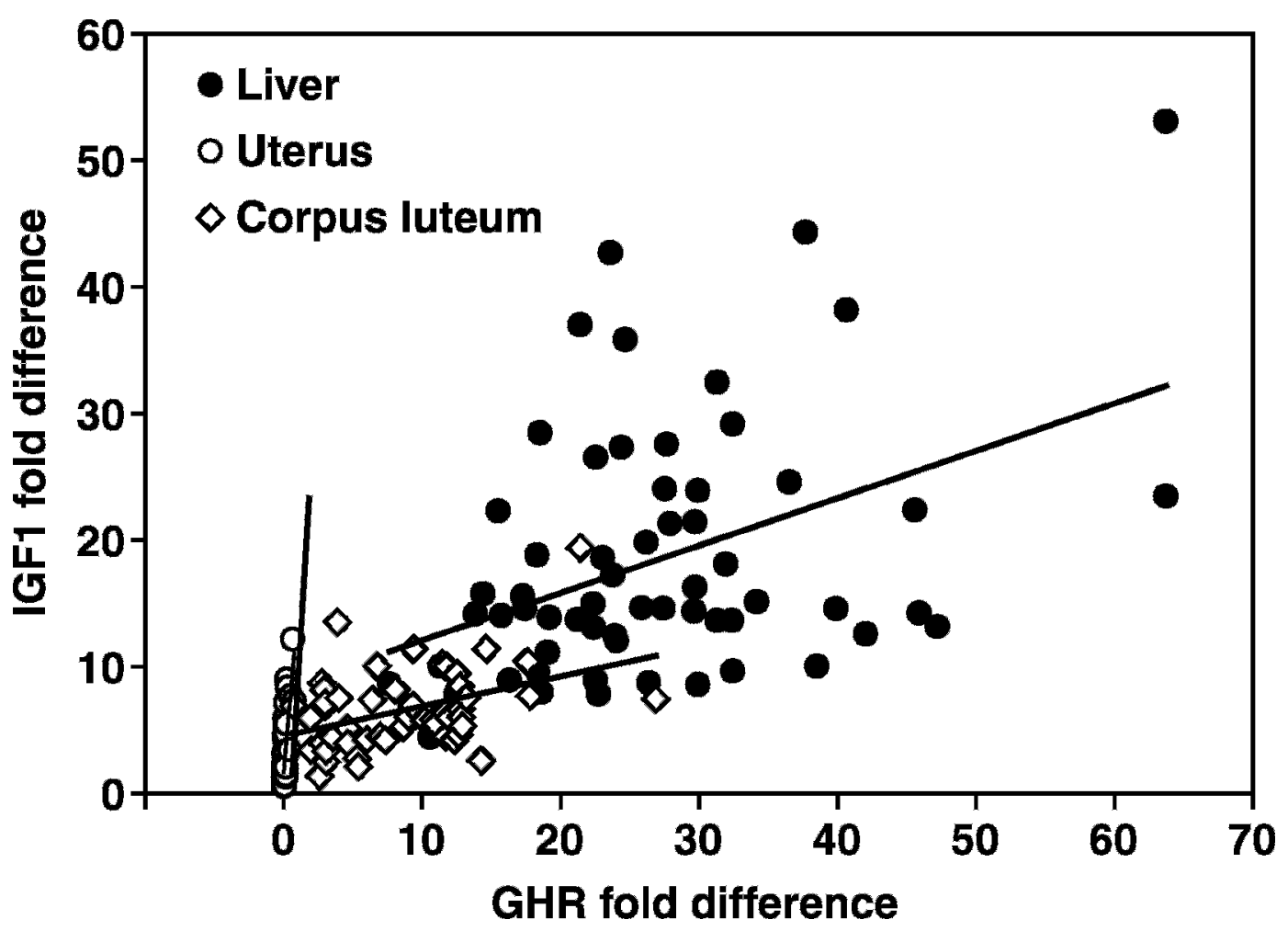

Figure 3. Regression of IGF-1 gene expression on growth hormone receptor (GHR) gene expression for liver, uterus, and corpus luteum. The equations for the regression lines are presented in Table 4 . In each case the regression is significant (different from 0 ) but the slope of the regression line depends on the tissue. Data are for cows sampled at 20, 40, and 60 DIM.

sampling period. In addition, plasma GH and IGF-1 concentrations were similar at all 3 DIM, indicating that by the time the sample collections began, the cows had already recovered from the hepatic GH resistance that occurs during the early postpartum period. This was unfortunate and unexpected but we could not have realistically sampled cows earlier postpartum and achieved the goal of sampling multiple tissues from the same cow.

Our analyses of gene expression demonstrated different levels of expression for IGF system genes in individual tissues. We found little evidence, however, for temporal regulation of their expression (i.e., little change from 20 to $60 \mathrm{DIM})$. Liver expressed the greatest amount of GHR, IGF-1, and IGFBP-2 mRNA (Table 2). The differences between liver and other tissues were large. The CL, the tissue with the second-most-abundant amounts for individual transcripts, expressed about one-third the amount of GHR and IGF-1 mRNA when compared with liver. The presence of a relatively large amount of GHR in CL compared with other reproductive tissues agreed with our previous work that demonstrated the presence of GHR mRNA in the large luteal cells (Lucy et al., 1993; Yuan and Lucy, 1996). Growth hormone acting via the GHR may play a role in progesterone synthesis within the CL (Juengel and Niswender, 1999). There was also GHR mRNA in the follicle (granulosa cells) and, in agreement with previous results, the amount of GHR in the bovine follicle was considerably less than what was found in the bovine CL (Lucy et al., 1993; Kirby et al., 1996). We also found a relatively large amount of IGF- 1 mRNA in the CL as well as in the DF. The follicular samples that we collected theoretically comprised granulosa cells that came free during the follicular aspiration. The presence of IGF-1 mRNA in the samples that we collected agrees with our previous work showing IGF-1 expression in the granulosa cell layer of the DF (Yuan et al., 1998). We observed relatively low expression (compared with liver) of IGFBP-2 in the DF, a finding that again agrees with our previous work on DF in cattle. We were somewhat surprised to observe extremely low levels of IGFBP-2 in the uterine samples. Very little work has been done in the cow on IGFBP-2 expression in the uterus. Robinson et al. (2000) found relatively low levels of IGFBP-2 expression in the subepithelial stroma but we detected appreciable quantities when the entire uterus was assayed for IGFBP-2 mRNA (Kirby et al., 1996). 
The only temporally affected gene was cyclophilin (greatest at $20 \mathrm{DIM}$ in uterus). Cyclophilin is an immunophilin (a class of cytosolic enzymes). The immunophilins are associated with cellular processes such as protein folding, protein tyrosine kinase receptor signaling, and stabilization of calcium release channels (Ivery, 2000). These processes could be upregulated in a tissue that is undergoing active remodeling and regeneration such as the involuting uterus. Other effects that were included in our statistical model were parity, milk production, and BCS. These effects were typically not significant for gene expression in individual tissues. We did observe an effect of parity on GHR in the CL with nearly 2 -fold more GHR in the CL of third or greater parity cows. We observed an effect of parity on IGFBP-2 in the uterus as well. We are not aware of any biological reasons for effects of parity on these genes and within these tissues. We did observe an effect of parity on plasma IGF-1 (reduced in older cows), and this observation was associated with a tendency for reduced IGF1 mRNA in the liver of older cows $(P=0.13)$. The decrease in IGF-1 in older cows is a consequence of "somatopause," a process through which IGF-1 declines in the blood of older individuals (Rosen, 2000). The decrease in liver IGF-1 mRNA reflects the fact that liver is the primary source of IGF-1 found in the bloodstream (Le Roith et al., 2001).

Tissue from the same cow was sampled multiple times and this sampling scheme enabled the calculation of repeatability, a measurement that can be used to assess the correlation among data collected from the same cow. We found that the repeatability for gene expression was typically in the range of 0.25 to 0.5 (Table 3) and this level was comparable to the repeatability for plasma GH and IGF-1 for cows from this trial. The greatest repeatabilities were found for IGF1 in which liver, uterus, and DF had relatively high repeatabilities. The greatest repeatability was for DF IGF-1 (0.91) and this was particularly interesting because the actual follicle was different at each sample collection. Likewise for CL, the repeatabilities for GHR, IGFBP-2, and cyclophilin for CL were all above 0.4 but a different CL was collected at each time. The implications are 2-fold. First, the high repeatability for IGF-1 implies that there are inherent characteristics of the cow that control IGF-1 expression in several different tissues (but apparently not CL, where the repeatability was low). This may relate to the importance of IGF-1 as a growth factor for a variety of biological processes in a wide range of tissues. The second implication is that for ovarian structures (DF and CL), their inherent capacity for gene expression is controlled by factors within the cow that impinge upon individual DF and
CL that arise from successive follicular waves and ovulatory events.

We analyzed the correlation of gene expression within and across tissues. The reason for this analysis was to determine if there was coordinated expression of genes in multiple tissues. For example, if a cow were relatively high for IGF-1 gene expression in liver, would she also be high for IGF-1 gene expression in uterus, $\mathrm{DF}$, and (or) CL? Conversely, if a cow were low for liver IGF-1, would other tissues be low as well? The clear answer to this question was that gene expression across tissues was not correlated (neither positively nor negatively). The expression of the genes that we tested in one tissue could not be used to predict gene expression in a second tissue. This observation leads to the conclusion that gene expression is not globally controlled, but rather that the control resides within the individual tissues of the cow. Factors that affect the whole animal can have unique effects at the level of each tissue.

We did, however, find a high correlation for gene expression within tissues (Table 4). Analyses of gene expression within a tissue involved the analysis of the same RNA sample so some of the correlation can perhaps be explained by the fact that both genes were assayed in the same sample. This argument is tempered somewhat by the fact that not all genes were correlated in every tissue. For example, there was a high correlation between GHR and cyclophilin in follicle but no correlation between GHR and IGF-1 in follicle. The correlated expression of 2 genes within the same tissue sample may simply reflect the overall transcriptional activity of the cells within the tissue sample. Some tissue samples may contain cells with greater overall transcriptional activity and this may manifest itself as greater expression for a variety of genes within the tissue sample. Correlations may also reflect cause and effect. We observed a correlation between GHR and IGF-1 in liver, uterus, and CL. This observation may imply that GH acting through the GHR promotes IGF1 gene transcription (a well-accepted biological process; Le Roith et al., 2001). We did not see this relationship in follicle where there was no correlation between GHR and IGF-1. The absence of a significant correlation agrees with a study that showed little effect of GH on ovarian IGF-1 expression (Cohick et al., 1996).

An interesting aspect of these analyses is that the linear relationship between 2 genes depended on the tissue from which the RNA was extracted (Table 4). For example, GHR and cyclophilin are highly correlated and this correlation exists within liver, uterus, DF, follicle, and CL (Table 4; Figure 2). Cyclophilin is a classical housekeeping gene and its expression has been used in the past to normalize data in gene expression studies (Rhoads et al., 2003). This use may be acceptable for 
samples arising from the same tissue. When examining the relationship between GHR and cyclophilin, however, it is clear that the relationship between the 2 genes depends on tissue. In liver, for example, a relatively small change in cyclophilin is associated with a large change in GHR. In uterus, the correlation (r) is equally strong but large changes in uterine cyclophilin are associated with only modest changes in GHR. This may mean that in a tissue such as liver, the factors that control cyclophilin have a large effect on GHR expression but the same is not true for uterus. When the relationship between IGF-1 and cyclophilin is examined (Figure 2B), the regression for liver and CL are reminiscent (in terms of slope) of the GHR and cyclophilin plot (Figure 2A). In uterus, however, a more positive relationship is seen and this may reflect greater responsiveness of IGF-1 gene expression to cyclophilin within uterine tissue.

Cause and effect are not established by linear regression. Nonetheless, an interesting relationship was observed between GHR and IGF-1 expression in liver, uterus, and CL. As stated above, GH acting through the GHR causes an increase in cellular IGF-1 expression. This increase in IGF-1 is caused by a signal transducer and activator of transcription (STAT) 5 binding site on the IGF-1 gene (Chia et al., 2006). Activation of STAT5 in response to GH causes an increase in IGF-1 gene transcription. Given this relationship, it makes sense that we observed a correlation between GHR and IGF-1 in liver and CL (Figure 3). A linear relationship between GHR and IGF-1 was also observed for uterus but the nature of the relationship is distinctly different in as much as small changes in uterine GHR led to large changes in uterine IGF-1. Perhaps this means that the uterine IGF-1 is highly sensitive to GH through the GHR. A small change in GHR in uterus may have major implications for uterine IGF-1 expression. This possibility would explain why dairy cows respond positively in terms of pregnancy rate to recombinant bST treatment (Moreira et al., 2001; Santos et al., 2004; Bilby et al., 2006). It also implies that a small positive change in uterine GHR could greatly increase endometrial IGF-1 production and improve early embryonic development by increasing the concentrations of growth factors in the uterine lumen.

\section{CONCLUSIONS}

Components of the GH/IGF system were investigated in the liver, uterus, DF, and CL of dairy cattle at 20 , 40 , and 60 DIM. Tissues differed for the expression of specific genes but the sampled tissues underwent little change in gene expression across the sampling interval. Neither level of milk production nor BCS affected gene expression in the respective tissues. Gene expression for most genes was moderately repeatable (i.e., individual cows accounted for most of the variability). Expression of a single gene within a tissue was generally correlated with other genes in the same tissue but was not correlated with the same gene in a different tissue. The linear relationship between the expression of 2 genes in any one tissue depended on the tissue itself. Small changes in gene expression for one gene, therefore, may have major implications for a second gene but the response is highly dependent on tissue.

\section{REFERENCES}

Bilby, T. R., A. Sozzi, M. M. Lopez, F. T. Silvestre, A. D. Ealy, C. R. Staples, and W. W. Thatcher. 2006. Pregnancy, bovine somatotropin, and dietary n-3 fatty acids in lactating dairy cows: I. Ovarian, conceptus, and growth hormone-insulin-like growth factor system responses. J. Dairy Sci. 89:3360-3374.

Butler, W. R. 2000. Nutritional interactions with reproductive performance in dairy cattle. Anim. Reprod. Sci. 60:449-457.

Chia, D. J., M. Ono, J. Woelfle, M. Schlesinger-Massart, H. Jiang, and P. Rotwein. 2006. Characterization of distinct Stat5b binding sites that mediate growth hormone-stimulated IGF-I gene transcription. J. Biol. Chem. 281:3190-3197.

Cohick, W. S., J. D. Armstrong, M. D. Whitacre, M. C. Lucy, R. W. Harvey, and R. M. Campbell. 1996. Ovarian expression of insulinlike growth factor-I (IGF-I), IGF binding proteins, and growth hormone $(\mathrm{GH})$ receptor in heifers actively immunized against GH-releasing factors. Endocrinology 137:1670-1677.

Gorewit, R. C. 1981. Pituitary, thyroid and adrenal responses to clonidine in dairy cattle. J. Endocrinol. Invest. 4:135-139.

Hunter, M. G., R. S. Robinson, G. E. Mann, and R. Webb. 2004. Endocrine and paracrine control of follicular development and ovulation rate in farm species. Anim. Reprod. Sci. 82-83:461-477.

Ivery, M. T. 2000. Immunophilins: Switched on protein binding domains? Med. Res. Rev. 20:452-484.

Izadyar, F., H. T. Van Tol, W. G. Hage, and M. M. Bevers. 2000. Preimplantation bovine embryos express mRNA of growth hormone receptor and respond to growth hormone addition during in vitro development. Mol. Reprod. Dev. 57:247-255.

Juengel, J. L., and G. D. Niswender. 1999. Molecular regulation of luteal progesterone synthesis in domestic ruminants. J. Reprod. Fertil. Suppl. 54:193-205.

Kirby, C. J., M. F. Smith, D. H. Keisler, and M. C. Lucy. 1997. Follicular function in lactating dairy cows treated with sustainedrelease bovine somatotropin. J. Dairy Sci. 80:273-285.

Kirby, C. J., W. W. Thatcher, R. J. Collier, F. A. Simmen, and M. C. Lucy. 1996. Effects of growth hormone and pregnancy on expression of growth hormone receptor, insulin-like growth factor-I, and insulin-like growth factor binding protein-2 and -3 genes in bovine uterus, ovary, and oviduct. Biol. Reprod. 55:996-1002.

Le Roith, D., C. Bondy, S. Yakar, J. L. Liu, and A. Butler. 2001. The somatomedin hypothesis: 2001. Endocr. Rev. 22:53-74.

Lucy, M. C. 2000. Regulation of ovarian follicular growth by somatotropin and insulin-like growth factors in cattle. J. Dairy Sci. 83:1635-1647.

Lucy, M. C. 2001. Reproductive loss in high-producing dairy cattle: Where will it end? J. Dairy Sci. 84:1277-1293.

Lucy, M. C. 2004. Mechanisms linking the somatotropic axis with insulin: Lessons from the postpartum dairy cow. Proc. N. Z. Soc. Anim. Prod. 64:19-23.

Lucy, M. C., R. J. Collier, M. L. Kitchell, J. J. Dibner, S. D. Hauser, and G. G. Krivi. 1993. Immunohistochemical and nucleic acid analysis of somatotropin receptor populations in the bovine ovary. Biol. Reprod. 48:1219-1227. 
Lucy, M. C., H. Jiang, and Y. Kobayashi. 2001. Changes in the somatotropin axis associated with the initiation of lactation. J. Dairy Sci. 84(E Suppl.):E113-E119.

McGuire, M. A., J. L. Vicini, D. E. Bauman, and J. J. Veenhuizen. 1992. Insulin-like growth factors and binding proteins in ruminants and their nutritional regulation. J. Anim. Sci. 70:29012910.

Moreira, F., C. Orlandi, C. A. Risco, R. Mattos, F. Lopes, and W. W. Thatcher. 2001. Effects of presynchronization and bovine somatotropin on pregnancy rates to a timed artificial insemination protocol in lactating dairy cows. J. Dairy Sci. 84:1646-1659.

Quintans, G., C. Vinoles, and K. D. Sinclair. 2004. Follicular growth and ovulation in postpartum beef cows following calf removal and GnRH treatment. Anim. Reprod. Sci. 80:5-14.

Radcliff, R. P., B. L. McCormack, B. A. Crooker, and M. C. Lucy. 2003a. Growth hormone (GH) binding and expression of GH receptor 1A mRNA in hepatic tissue of periparturient dairy cows. J. Dairy Sci. 86:3933-3940.

Radcliff, R. P., B. L. McCormack, B. A. Crooker, and M. C. Lucy. 2003b. Plasma hormones and expression of growth hormone receptor and insulin-like growth factor-I mRNA in hepatic tissue of periparturient dairy cows. J. Dairy Sci. 86:3920-3926.

Radcliff, R. P., B. L. McCormack, D. H. Keisler, B. A. Crooker, and M. C. Lucy. 2006. Partial feed restriction decreases growth hormone receptor 1A mRNA expression in postpartum dairy cows. J. Dairy Sci. 89:611-619.

Rhoads, M. L., J. P. Meyer, W. R. Lamberson, D. H. Keisler, and M. C. Lucy. 2008. Uterine and hepatic gene expression in relation to days postpartum, estrus and pregnancy in postpartum dairy cows. J. Dairy Sci. 91:140-150.

Rhoads, R. P., C. McManaman, K. L. Ingvartsen, and Y. R. Boisclair. 2003. The housekeeping genes GAPDH and cyclophilin are regulated by metabolic state in the liver of dairy cows. J. Dairy Sci. 86:3423-3429.

Robinson, R. S., G. E. Mann, T. S. Gadd, G. E. Lamming, and D. C. Wathes. 2000. The expression of the IGF system in the bovine uterus throughout the oestrous cycle and early pregnancy. J. Endocrinol. 165:231-243.

Roche, J. F. 2006. The effect of nutritional management of the dairy cow on reproductive efficiency. Anim. Reprod. Sci. 96:282-296.
Rosen, C. J. 2000. Growth hormone and aging. Endocrine 12:197-201. Santos, J. E., S. O. Juchem, R. L. Cerri, K. N. Galvao, R. C. Chebel, W. W. Thatcher, C. S. Dei, and C. R. Bilby. 2004. Effect of bST and reproductive management on reproductive performance of Holstein dairy cows. J. Dairy Sci. 87:868-881.

Thatcher, W. W., A. Guzeloglu, A. Meikle, S. Kamimura, T. Bilby, A. A. Kowalski, L. Badinga, R. Pershing, J. Bartolome, and J. E. Santos. 2003. Regulation of embryo survival in cattle. Reprod. Suppl. 61:253-266.

Thissen, J. P., J. M. Ketelslegers, and L. E. Underwood. 1994. Nutritional regulation of the insulin-like growth factors. Endocr. Rev. 15:80-101.

Vasconcelos, J. L., R. W. Silcox, G. J. Rosa, J. R. Pursley, and M. C. Wiltbank. 1999. Synchronization rate, size of the ovulatory follicle, and pregnancy rate after synchronization of ovulation beginning on different days of the estrous cycle in lactating dairy cows. Theriogenology 52:1067-1078.

Wathes, D. C., T. S. Reynolds, R. S. Robinson, and K. R. Stevenson. 1998. Role of the insulin-like growth factor system in uterine function and placental development in ruminants. J. Dairy Sci. 81:1778-1789.

Watson, A. J., M. E. Westhusin, and Q. A. Winger. 1999. IGF paracrine and autocrine interactions between conceptus and oviduct. J. Reprod. Fertil. Suppl. 54:303-315.

Webb, R., P. C. Garnsworthy, J. G. Gong, and D. G. Armstrong. 2004. Control of follicular growth: Local interactions and nutritional influences. J. Anim. Sci. 82(E Suppl.):E63-E74.

Wook Kim, J., R. P. Rhoads, S. S. Block, T. R. Overton, S. J. Frank, and Y. R. Boisclair. 2004. Dairy cows experience selective reduction of the hepatic growth hormone receptor during the periparturient period. J. Endocrinol. 181:281-290.

Yuan, W., B. Bao, H. A. Garverick, R. S. Youngquist, and M. C. Lucy. 1998. Follicular dominance in cattle is associated with divergent patterns of ovarian gene expression for insulin-like growth factor (IGF)-I, IGF-II, and IGF binding protein-2 in dominant and subordinate follicles. Domest. Anim. Endocrinol. 15:55-63.

Yuan, W., and M. C. Lucy. 1996. Messenger ribonucleic acid expression for growth hormone receptor, luteinizing hormone receptor, and steroidogenic enzymes during the estrous cycle and pregnancy in porcine and bovine corpora lutea. Domest. Anim. Endocrinol. 13:431-444. 